\title{
Greasing Their Way: Lipid Modifications Determine Protein Association with Membrane Rafts ${ }^{\dagger}$
}

\author{
Ilya Levental, Michal Grzybek, and Kai Simons* \\ Max Planck Institute of Molecular Cell Biology and Genetics, Pfotenhauerstrasse 108, 01307 Dresden, Germany
}

Received June 1, 2010; Revised Manuscript Received June 25, 2010

\begin{abstract}
Increasing evidence suggests that biological membranes can be laterally subdivided into domains enriched in specific lipid and protein components and that these domains may be involved in the regulation of a number of vital cellular processes. An example is membrane rafts, which are lipid-mediated domains dependent on preferential association between sterols and sphingolipids and inclusive of a specific subset of membrane proteins. While the lipid and protein composition of rafts has been extensively characterized, the structural details determining protein partitioning to these domains remain unresolved. Here, we review evidence suggesting that post-translation modification by saturated lipids recruits both peripheral and transmembrane proteins to rafts, while short, unsaturated, and/or branched hydrocarbon chains prevent raft association. The most widely studied group of raft-associated proteins are glycophosphatidylinositolanchored proteins (GPI-AP), and we review a variety of evidence supporting raft-association of these saturated lipid-anchored extracellular peripheral proteins. For transmembrane and intracellular peripheral proteins, S-acylation with saturated fatty acids mediates raft partitioning, and the dynamic nature of this modification presents an exciting possibility of enzymatically regulated raft association. The other common lipid modifications, that is, prenylation and myristoylation, are discussed in light of their likely role in targeting proteins to nonraft membrane regions. Finally, although the association between raft affinity and lipid modification is well-characterized, we discuss several open questions regarding regulation and remodeling of these post-translational modifications as well as their role in transbilayer coupling of membrane domains.
\end{abstract}

As membranes comprise a large proportion of cellular biomass, it is perhaps not surprising that $25-40 \%$ of eukaryotic cellular proteins are membrane associated (1). Membrane proteins require specialized structures, which can be either proteinaceous or lipidic, to allow them to embed in the hydrophobic environment of the lipid bilayer. Membrane spanning (or inserting) protein domains are typically $\alpha$-helices or $\beta$-sheets with hydrophobic surfaces serving as the interface to the hydrocarbon core of the lipid bilayer. In addition to, or as a replacement for, hydrophobic protein domains, membrane association can be mediated by lipidic anchors, which can either be permanent cotranslational additions or post-translational modifications under dynamic enzymatic control. These lipid modifications include (1) glycophosphatidylinositol (GPI) ${ }^{1}$ anchors; (2) N-terminal myristic acid tails; (3) cysteine acylation; (4) isoprenylation; and (5) the addition of $\mathrm{C}$-terminal sterol moieties.

\footnotetext{
"The authors would like to acknowledge funding from the Humboldt Foundation Postdoctoral Research Fellowship, EUFP6 "PRISM" LSHB-CT2007-037740, DFG Schwerpunktprogramm 1175 Contract No. SI459/2-1, BMBF "BioChance Plus" Grant 0313827, and BMBF "ForMaT" Grant 03FO1212.

*To whom correspondence should be addressed. Phone: +49-(0)3512101200. Fax: +49-(0)351-2101209. E-mail: simons@mpi-cbg.de.

Abbreviations: GPI-AP, glycophosphatidylinositol-anchored protein; TGN, trans-Golgi network; LAT, linker for activation of T-cells; MDCK, Madin-Darby canine kidney; DRM, detergent resistant membrane; HA, hemagglutinin; PM, plasma membrane; SFK, src-family kinase; TMD, transmembrane domain; GPMV, giant plasma membrane vesicle; PMS, plasma membrane spheres; TCR, T-cell receptor; IS, immune synapse; TX100, Triton X-100; Hh, hedgehog; PUFA, poly unsaturated fatty acid.
}

Significant evidence has been generated over the last two decades to suggest that the lipids and proteins of the eukaryotic plasma membrane are not homogeneously distributed, but that they can segregate into dynamic subdomains, the most prominent example of which are membrane rafts. In eukaryotic cells, these rafts are the biological result of preferential interactions between sphingolipids and sterols that manifest themselves as small and dynamic domains that can cluster and segregate specific membrane components (2). Underlying the functionality of membrane rafts is their selectivity for proteins effectors including receptors, scaffolding molecules, and secondary signal transducers. In this review, we summarize evidence supporting the hypothesis that lipid modifications are an important determinant of protein partitioning between raft and nonraft domains, with saturated hydrocarbon chains and sterols promoting raft association while short, branched, and/or unsaturated acylations prevent protein partitioning into the tightly packed raft microenvironment (Figure 1).

\section{GPI-ANCHORS: RAFT-ASSOCIATING MODIFICA- TION FOR EXTRACELLULAR PROTEINS}

Perhaps the most well-characterized examples of lipid modifications determining protein association with membrane rafts are GPI-anchored proteins (GPI-APs). GPI-APs are a widely expressed class of proteins that are involved in a variety of cellular functions including adhesion, membrane trafficking, immune system signaling, and nutrient uptake (reviewed in refs 3 and 4). The GPI-anchor consists of a conserved core oligosaccharide 


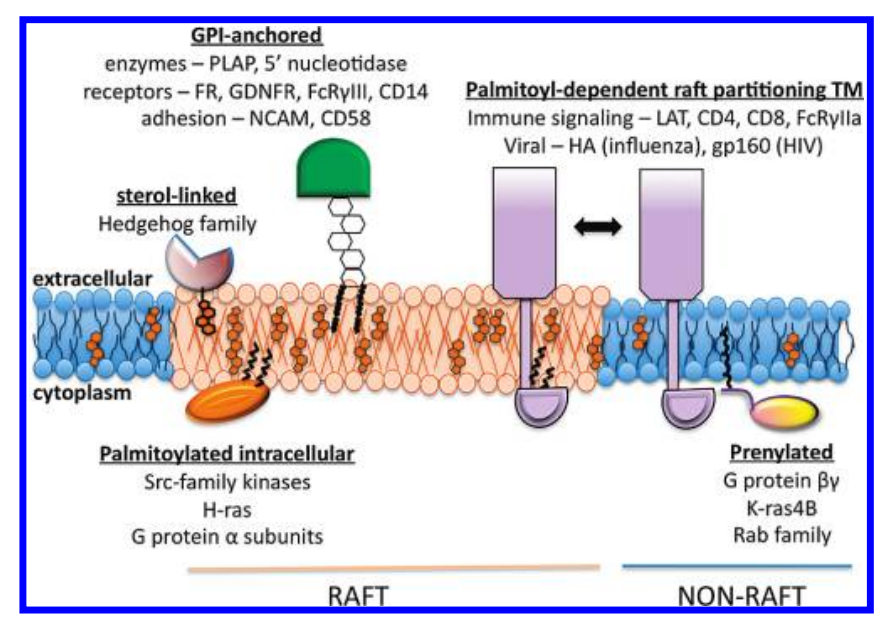

FIGURE 1: Examples of lipid modification of proteins. Various lipid anchors play important roles in protein trafficking, membrane partitioning, and proper function, likely mediated by their affinity for lipid rafts. The general paradigm is that anchoring by saturated fatty acids (as for GPI-anchored proteins and palmitoylated intracellular and TM components) and sterols (for Hh proteins) targets proteins to the more tightly packed environment of lipid rafts, while unsaturated and branched hydrocarbon chains tend to favor the less restrictive nonraft membranes.

covalently coupled to a phosphoinositide moiety that is embedded in the lumenal/exoplasmic leaflet through at least two (sometimes three) glycerol-linked acyl or alkyl chains. This anchor is added in toto in the lumen of the ER to soluble polypeptides, thereby confering membrane association $(4,5)$.

Detergent-Resistant Membranes - The Genesis of the Raft Hypothesis. During the latter steps of the secretory pathway, GPI-APs acquire the detergent resistance that was the original biochemical hallmark of raft association $(6,7)$. These proteins were the first ones identified to possess affinity for detergent-resistant membranes (DRMs) and remain the most widely studied group of raft-associated proteins. The fact that their detergent resistance is acquired during trafficking through the trans-Golgi network (TGN) suggests that this biochemical distinction is a consequence of the association of GPI-APs with a specific membrane environment, rather than some inherent property of the protein or anchor (6). The proposed physiological function of raft partitioning of GPI-APs was to aid in sorting of these proteins to the apical membrane of polarized epithelial cells (7), first demonstrated in Madin-Darby canine kidney (MDCK) cells, a widely used model epithelial cell line that polarizes into distinct, well-separated apical and basolateral domains when cultured on porous filters. In MDCKs (8) and several other cell types (9), GPI-APs are apically directed and the addition of a GPI anchor can reroute normally basolaterally targeted proteins to the apical domain (10). Apical trafficking and detergent resistance of GPI-APs could be disrupted by treatments that deplete either membrane cholesterol or sphingolipids (both of which disrupt membrane rafts), further supporting the notion that raft association mediates apical trafficking for this subset of proteins (11-13). Similarly, the lipid structure of the GPI anchor was shown to be critical for detergent resistance of GPI-APs, as shorter hydrocarbon chains (C14), which would not be expected to be raft preferring, failed to confer DRM association (14).

Importantly, detergent resistance of GPI-anchored, and indeed most other, proteins is strictly dependent on the solubilization conditions; for example, the same GPI-APs (7) and lipids (15) that are resistant to Triton X-100 (TX100) are soluble in another nonionic detergent, CHAPS. This discrepancy highlights an important consideration for the interpretation of detergent resistance experiments, that is, that detergent resistance of membrane fractions is in itself an inherently artifactual phenomenon (16) and therefore great care must be taken in assigning biological meaning to findings relying strictly on detergent resistance for assigning raft association. While detergent resistance has been and remains a useful tool for membrane fractionation and analysis, more biologically appropriate methods have been devised that have confirmed and extended many of the important predictions of the raft hypothesis $(17,18)$.

Micropatching of GPI-APS and Intracellular Raft Proteins. Key results confirming GPI-AP enrichment in specific membrane domains were provided by a set of experiments measuring the coclustering of membrane components following antibody crosslinking of specific components on live-cell membranes. Treatment of live cells with primary antibodies against plasma membrane components, followed by secondary antibody crosslinking, leads to microscopically observable clusters enriched in the protein of interest (19). Strikingly, clusters induced by crosslinking the GPI-AP placental alkaline phosphatase (PLAP) exhibited significant overlap with patches of other putative raft components (i.e., influenza hemagglutinin (HA) and the ganglioside glycolipid GM1), while excluding both transferrin (TfR) and low density lipoprotein receptor (LDLR) patches (20). Antibody-induced patching was sensitive to the depletion of plasma membrane cholesterol, confirming that the observed patches were the result of coalescence of existing, selective protein and lipid assemblies that are below the resolution of light microscopy in the absence of cross-linking. Similar copatching behavior observed for the GPI-AP Thy-1 and the raft glycolipid GM1 in immune cells confirmed the general nature of this phenomenon and specific enrichment of GPI-APs in raft domains of various cell types. Perhaps most importantly, patches induced by crosslinking PLAP (whose lipid anchor is embedded in the extracellular leaflet of the plasma membrane) accumulated the Srcfamily kinase (SFK) Fyn (which interacts with the PM only through acylations embedded in the intracellular leaflet) without patching of the cytoplasmic protein (20). This result confirmed the possibility of signal transduction through raft microdomains by interaction and coenrichment of proteins anchored to opposing leaflets, though the mechanism of this interaction remains to be defined. Further work revealed that patched rafts could serve as signaling hotspots for phosphorylation and cytoskeletal rearrangement (21), confirming their importance in lymphocyte cell biology (reviewed in ref 22).

The resting state association of GPI-APs implied by the copatching experiments was confirmed by an elegant nanoscopic study measuring the fluorescence resonance energy transfer (FRET) between folate molecules bound to their GPI-anchored receptors. Cholesterol-dependent nonrandom clustering of GPIanchored folate receptor was observed, in contrast to homogeneous arrangement of the same receptor anchored to the PM by a transmembrane (TM) polypeptide (23), and these studies were subsequently extended to define the size, trafficking, composition, and abundance of these clusters (24). These results were confirmed by chemical cross-linking analysis, which showed that cross-linked oligomers of a model protein could only be formed when membrane anchoring was accomplished with GPI (25).

Confirmation of GPI-AP Raft Association with High Resolution Microscopy and Purified Membranes. Recent advancements in microscopy and preparation of model membranes 
have allowed high resolution measurement of GPI-AP distribution and dynamics that have confirmed and extended the original results associating GPI-APs with raft subdomains. For example, a nanoscopic fluorescence method, single-molecule microscopy, was recently used to image GPI-APs arranged in hierarchical clusters proximal to clustered integrin receptors that can be activated inducing coalescence into preoligomerized sites for adhesion (26). Microscopic confinement on a similar length scale was also observed by dynamical tracking of single GPI-APs on the surface of live cells, demonstrating that $30-40 \%$ of both Thy-1 and the raft glycolipid GM1 were transiently retained in regions of cell-dependent sizes of $30-230 \mathrm{~nm}(27-29)$. These zones were shown to recruit cytosolic leaflet signaling proteins (30), confirming earlier copatching results, although the relative involvement of the lipid environment and cytoskeletal scaffold to this constrained diffusion remains under debate (31).

An important and direct measure of component partitioning between coexisting fluid domains has been provided by observations of reconstituted proteins in model membranes with microscopic phase coexistence. The original experiments of this type used mixtures of synthetic lipids reconstituted to form membranes in which fluid-fluid phase separation can be observed for a range of concentrations and temperatures (32). Thy-1 reconstituted into a supported monolayer containing a phase separating mixture of raft lipids (sphingomyelin, an unsaturated phosphatidylcholine, and cholesterol) partitioned significantly into the model raft domain, and this affinity was enhanced in a natural lipid mixture derived from the brush border membrane (33). Similar results were obtained when PLAP was incorporated into a model bilayer prepared by electroformation; here PLAP partitioned into the ordered phase (although was not enriched there), and this partitioning could be greatly enhanced by antibody-mediated oligomerization (34). This paper speculated that the lack of enrichment of the protein in the ordered phase was due to an unphysiologically tight packing of the model membrane Lo phase (recently confirmed by biophysical measurements (35)), and this was confirmed by convincing evidence of GPI-AP enrichment in ordered phases of biological membranes (36). An exciting new direction in membrane research is the observation of coexisting fluid phases in either cell-derived plasma membrane vesicles (GPMVs) (37) or inflated plasma membranes spheres of whole cells (PMS) (38). In both cases, pronounced enrichment of GPI-APs was observed in the phase enriched in GM1 (among other raft components) and depleted of disordered phase markers (37-39).

Progress in the field has led to the evolution of experimental techniques for defining the molecular composition of lipid rafts from a strict reliance on differential detergent resistance to nanoscopic measurements of interprotein distance and dynamics to, most recently, observation of microscopic phase separation in biological membranes. The general conclusion of all these studies is that GPI-anchored proteins, at least mature proteins containing the most common saturated lipid anchors (reviewed in refs 4 and 5), are constitutively enriched in raft domains at the cell surface.

\section{CYSTEINE PALMITOYLATION - RAFT-ASSO- CIATING MODIFICATION FOR INTRACELLULAR PROTEINS}

Novel isolation techniques combined with high-throughput proteomics have recently identified the wide extent of intracellular protein S-acylation (typically termed "palmitoylation" because

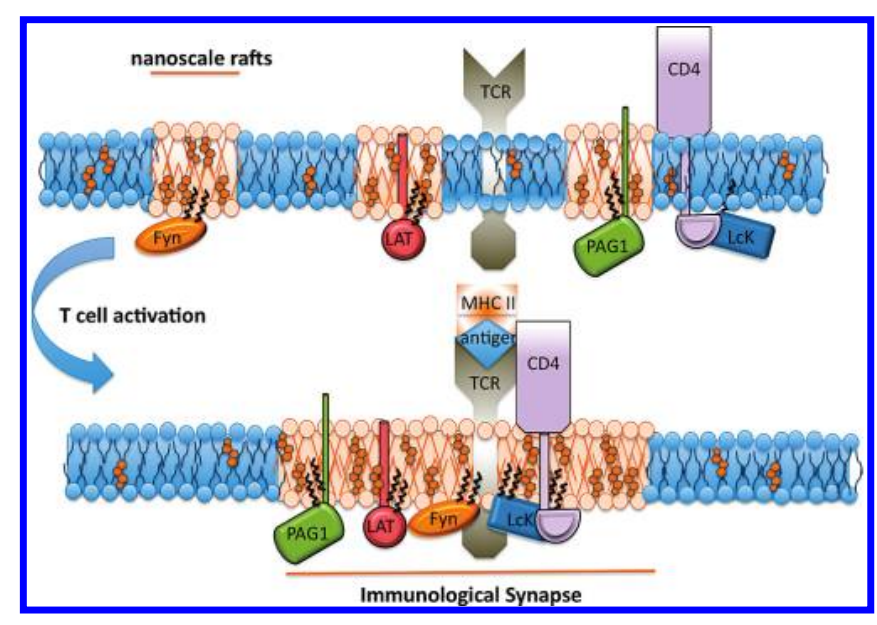

FIGURE 2: Lipid modification of proteins is suggested to play an important role in their association with the immunological synapse. Resting T cells contain small, dynamic lipid rafts, each with a limited number of associated molecules, which cluster upon activation to form a functional raft domain - the immunological synapse. Many of the proteins that form the IS are lipid modified and this modification is crucial for their partitioning to the IS. Model adapted from refs 55 and 56 .

the "palmitic", that is, C16:0, is the most commonly observed, though not only, S-acylation) (40-42). For many important signaling second messengers without a proteinaceous membrane anchor, including members of the Src-family of kinases (SFKs) and the Ras family of small GTPases, acylation is required for membrane attachment and function. However, in the case of integral membrane proteins embedded in the membrane through their hydrophobic polypeptides, a clear role for lipidic modification remains elusive. In contrast to the other common lipid modifications mentioned in this review (GPI, myristoylation, and prenylation), S-acylation is the only one that can be dynamically regulated by enzymes, that is, the lifetime of the modification is shorter than the lifetime of the protein it is modifying. Additionally, significant biochemical evidence points to cysteine modification by saturated fatty acids as a potential mechanism for raft localization for a variety of proteins. Thus, for both otherwise soluble and membrane embedded proteins, palmitoylation may act as a dynamically regulated control mechanism determining raft domain association in a variety of physiological contexts.

Immune Cell Signaling. In physiological analogy to exogenous antibody cross-linked clusters discussed above, recognition by the T-cell receptor (TCR) of its cognate ligand presented on major histocompatibility class (MHC) molecules leads to the condensation of signaling molecules into a microscopic plasma membrane domain (known as the immune synapse (IS)). This structure, important for cell attachment and subsequent downstream signaling, is enriched in several components present in DRMs, leading to the hypothesis (reviewed in refs 43 and 44) that coalescence of pre-existing membrane rafts is an important driver of IS assembly (Figure 2). In support of this model, it was shown that the SFK Lck (45) and its substrate Fyn (46) are DRMassociated, but only when acylated by saturated palmitic acid (47). These molecules are critically involved in signal transduction following TCR engagement, and when palmitoylation was either inhibited (47) or replaced by unsaturated fatty acylation (48), T-cell signaling was abrogated concomitant with the loss of detergent resistance for these proteins, correlating SFK raft localization and activity. Palmitoylation-dependent raft localization was also inferred for the T-cell transmembrane 
coreceptor CD4, through both DRM association $(49,50)$ and antibody-induced cross-linking (51), while interaction with the palmitoylated SFK Lck was required for its raft aggregating (5l) and T-cell stimulatory activity (52). Analogously palmitoylation (53) and DRM association (50) were shown for the cytotoxic T-cell coreceptor component CD8 $\beta$. Palmitoylation-dependent CD4 raft-association is challenged by findings that detergentresistance depends on a short sequence of positively charged residues in the membrane proximal cytosolic domain (54) independent of palmitoylation, highlighting the notorious variability of detergent resistance experiments and the necessity of confirmatory experiments using more direct methods.

The integral involvement of palmitoylated and raft-associated proteins has led to a model of raft-dependent activation of T-cell signaling wherein Lck is either palmitoylated or released from inhibitory binding upon ligand-binding-initiated interaction of CD4 with the T-cell receptor. Lck then translocates to raft domains due to its palmitoyl anchor (and a specific C-terminal sequence (55)) and phosphorylates Fyn, initiating downstream signaling (for details, see excellent review in ref 56).

Downstream of TCR engagement and phosphorylation, one of the best studied immune system proteins in signaling through lipid rafts is the transmembrane adaptor, linker for activation of T cells (LAT). Phosphorylation of LAT downstream of Lck activation leads to the recruitment of a variety of effectors including Grb2, PI3K, and PLC- $\gamma 1$ leading to T-cell signaling (57). Palmitoylation of LAT at two juxtamembrane cysteines was shown to be required for both detergent resistance and functionality, as palmitoylation-deficient mutants were not enriched at the IS, hypophosphorylated in response to TCR stimulation (58), and failed to induce the calcium fluxes indicative of T-cell activation (59). Intriguingly, a selective defect in LAT palmitoylation was observed in anergic T-cells (60), connecting palmitoylation-dependent raft association with a physiological function in moderating the immune response. Recent attempts to clarify the role of palmitoylation and raft association in LAT signaling have revealed that PM arrival of LAT is impaired by the palmitoylation defects and that nonpalmitoylated PM-targeted domains can restore LAT functionality irrespective of DRM association $(61,62)$. These findings suggest a role of LAT raft partitioning in regulating intracellular trafficking and raise important questions about the necessity of raft localization for LAT's function in T-cell signal transduction, although the activity of nonraft associated LAT has recently been shown to be dependent on the level of fusion protein expression (63).

Analogous to raft-dependent T-cell signaling, involvement of palmitoylation-dependent raft localization was observed for signaling through the IgG antibody receptor FcR $\gamma$ IIa. Activation is accomplished by cross-linking and patching of the receptor and downstream signaling components by antibody-coated foreign particles (64) and leads to phagocytosis of the particle by neutrophils and macrophages. Palmitoylation and DRM association of both the receptor (65) and its critical SFK Lyn (64) are required for cell activation and function.

The findings summarized above strongly support the hypothesis that condensation of raft domains containing both intracellular and TM proteins targeted to the ordered phase by saturated acylation facilitate immune system signaling through spatiotemporal control of concentration and molecular interactions in the plane of the plasma membrane (reviewed in refs 44 and 43). This hypothesis has been critically questioned $(66,67)$, largely due to the reliance of key supporting data on detergent resistance. In line with these criticisms, it is important to emphasize that the presence of a certain protein in a detergent-resistant fraction does not necessarily imply its preference for, or even association with, a subdomain of the plasma membrane, nor even that detergent-resistant membranes translate directly to the presence of such subdomains $(68,69)$. Nevertheless, detergent resistance has been an important tool for assigning raft association, and many of the conclusions drawn from those experiments have been validated by more sophisticated methods. For example, specific immuno-isolation and lipid analysis of the IS showed enrichment of raft lipids (70). Similarly, palmitoylation-dependent detergent resistance of LAT correlating with its ability to support signaling implicate protein selective ordered lipid domains as an important component of immune signaling. LAT was also observed to enrich in the condensed phase of plasma membrane spheres (as was a doubly palmitoylated model protein), confirming its preferred association with ordered phases (38). This finding was in contrast to the observation that a palmitoylated LAT peptide does not partition to the ordered phase of synthetic raft-model liposomes (71), possibly due to the exaggerated order/ packing differences between the two phases (35) or the lack of compositional complexity in pure lipid model systems.

Viral Assembly and Infection. Enveloped viruses exiting from infected host cells must organize native plasma membrane lipids and exogenously expressed viral proteins to form a specific envelope. It has been hypothesized that lateral sorting and enrichment mediated by membrane rafts can facilitate this process, and that some viruses, including influenza (72), HIV (73), measles (74), ebola (75), and Rous sarcoma (76), co-opt PM raft machinery for both assembly and entry (reviewed in refs 77 and 78 ). Evidence for this hypothesis was initially generated, as for many raft-related phenomena, by detergent-resistance experiments. Both external components of the influenza virus membrane, the spike glycoproteins hemagglutinin (HA) (7), and neuraminidase (NA) (79) were shown to be resistant to TX100 solubilization. Enrichment of raft lipids was confirmed in influenza virus envelope by lipid analysis and fluorimetric polarization, which showed that the envelope of the raft virus FPV (fowl plague virus, a member of the influenza family) was less fluid than for similar nonraft viruses (80).

For influenza HA, palmitoylation at three highly conserved membrane proximal cysteines (81) is important for both DRM association (82) and viral assembly (83). Intriguingly, a recent investigation suggests that the cysteine buried in the TM domain (TMD) is specifically modified with a stearic (18-carbon saturated), rather than a palmitic (16-carbon saturated) acid (84), a feature that appears to be common to viral glycoproteins (85) whose functional consequences remain to be clarified. The speculated link between palmitoylation-dependent raft association and HA function has been confirmed by electron microcopy, where enrichment of palmitoylated HA in $200-300 \mathrm{~nm}$ domains compared to random PM distribution of the nonraft associating mutant was observed and shown to be required for viral fusion (86). Similarly, HA was observed to diffuse slowly and cluster with acylated raft markers (by fluorescent recovery after photobleaching (FRAP) and fluorescence lifetime FRET (FLIMFRET), respectively) only when palmitoylation sites were preserved (87). Recent observations of HA partitioning in GPMVs have microscopically confirmed the potential for HA association with an ordered phase (39).

Analogous to influenza HA, palmitoylation-dependent DRM association and function was observed for the envelope 


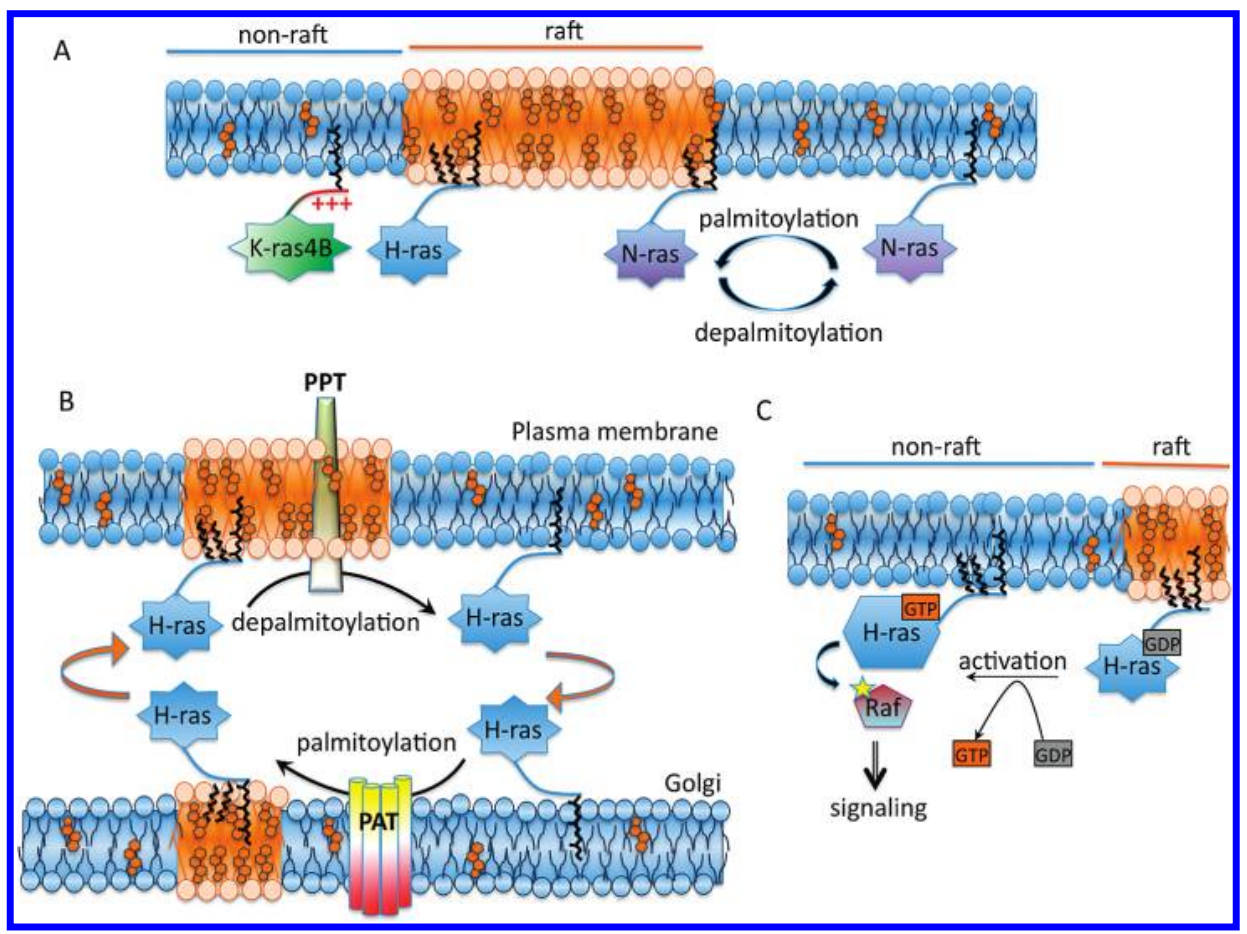

Figure 3: Palmitoylation in Ras partitioning, trafficking, and activity. (A) Although all Ras proteins are prenylated, this modification is not sufficient for their association with the plasma membrane. K-Ras4B contains a polybasic stretch of amino acids in its carboxyl terminus, and this isoform seems to be exclusively present in nonraft domains of the plasma membrane (112). Doubly palmitoylated H-Ras can partition to lipid rafts, while singly palmitoylated N-Ras has been observed at domain boundaries (156); for both, this localization is palmitoylation dependent. (B) When depalmitoylated by PPT enzymes, H and N-Ras cycle back to Golgi membranes, where they are repalmitoylated by Golgi resident PAT enzymes. Palmitoylation leads to recycling to the plasma membrane (114). (C) Activation of H-Ras leads to exchange of GDP to GTP and a conformational change in the membrane proximal domain of H-Ras, driving it out of membrane rafts and activating its downstream effector proteins (e.g., Raf) (113).

glycoprotein gp160 of the human immunodeficiency virus (HIV1) (88). DRM association correlates with evidence suggesting that HIV budding (89) and infection (90) is mediated by interaction with PM rafts. Infectivity of HIV requires interaction of viral gp120 with its cellular receptor CD4 (discussed in the immune signaling section above) leading to clustering of gp120-CD4CCR5 (an HIV coreceptor) complexes (91). This process has been proposed to be raft-mediated (90), and in support of this model, a chimeric CD4 construct targeted to nonraft membranes by exchange of its TMD for the TMD of the low density lipoprotein receptor (LDLR) (though not through inhibition of palmitoylation $(54,92))$ failed to support HIV infection (93).

Trimeric GTPase $\alpha$ Subunits. Although rafts are normally thought to be mediated by interaction between sterols and sphingolipids in the exoplasmic leaflet of the plasma bilayer, transbilayer coupling between leaflets leading to raft signaling in the intracellular leaflet has been proposed (94), inferred by antibody patching (20), and most recently demonstrated directly in a lipid raft model system (95). An important class of intracellular proteins whose raft association appears to be mediated by palmitoylation is that of the GTP-binding switches, including both trimeric G-proteins (reviewed in ref 96) and the small GTPases of the Ras family (reviewed in ref 97). For example, the $\alpha$ subunit of the heterotrimeric $\mathrm{G}_{12}$ protein associates with detergent-resistant membranes, but only when it is palmitoylated (98), its raft localization possibly explaining the distinct functions of $\mathrm{G}_{12}$ and the homologous $\mathrm{G}_{13}$. Similarly, palmitoylation (together with $\mathrm{N}$-terminal myristoylation) of a widely conserved MGC motif $(99,100)$ was required for efficient partitioning of $\mathrm{G}_{\mathrm{i} 1} \alpha$ to detergent-resistant membrane fractions $(99,101)$. These results were extended to model systems in which G-protein subunits were reconstituted into synthetic lipid vesicles. In these experiments, modification of the MGC motif with saturated (but not unsaturated) fatty acids was necessary not only for model membrane association, but also for resistance to TX100 solubilization (102) of the $\mathrm{G} \alpha$ subunits, whereas the farnesylated $\beta \gamma$ subunits remained detergent labile.

Interestingly, it has been documented that palmitate turnover of $\mathrm{G} \alpha$ subunits is regulated by agonist stimulation of the G-protein coupled receptors (GPCR). This was the case for Gs $\alpha$ association with the $\beta$-adrenergic receptor $(103,104)$ as well as $\mathrm{G}_{\mathrm{q} / 11}$ linked to activation of the gonadotropin-releasing hormone receptor (105). A possible mechanism to explain these results and the functional relevance of palmitoylation-dependent raft association of G-protein $\alpha$ subunits is that when the $\alpha$ subunits are associated with the $\beta \gamma$ proteins, the nonraft associated branched/unsaturated fatty acid modifications of those subunits retain the complex in nonraft membranes (as observed in ref 102). Following agonist-induced receptor activation, $\mathrm{G} \alpha$ is released and proceeds to the raft domain due to the preference of the long, saturated palmitic acid for ordered domains (102), where it can encounter a raft-associated thioesterase (e.g., PPT1 (106)), which removes the palmitoylation leading to $\mathrm{G} \alpha$ release from the plasma membrane (103). Alternatively, palmitoylated and raft-associated regulators of G-protein signaling (RGS) could activate inherent $\mathrm{G} \alpha$ GTPase activity, thereby inactivating signaling (e.g., RGS-16 (107)). This putative function of $\mathrm{G} \alpha$ palmitoylation is in addition to its recognized role in G-protein trafficking, where it appears necessary for Golgi-toPM transport of the intact trimer (108). Although the involvement of rafts in this process has yet to be investigated, it may be analogous to the palmitoylation-dependent trafficking of the Ras-GTPases described below. 
Src-Family Kinases. The functional relevance of palmitoylation and raft-association of several SFKs (including Fyn, Lck, and Lyn) were discussed above in their involvement in immune system signaling, and several other SFK members including hck (109) and yes (82) are palmitoylated and DRM associated. Although Src itself is not palmitoylated and excluded from rafts, introduction of an exogenous palmitoylated cysteine into the sequence induced its mis-sorting to rafts (110), emphasizing the strong relationship between this lipidation and raft association. Palmitoylation is thought to play a role in the regulation of these important signaling intermediates through a palmitoylated, raftassociated transmembrane adaptor phosphoprotein associated with glycosphingolipid-enriched microdomains, or PAG. This protein associates with rafts (as inferred from its DRM localization) and interacts with the major negative regulator of SFKs, C-terminal Src kinase (Csk) (111).

Ras GTPases. Similarly, raft-association is mediated by palmitoylation of the Ras GTPases, most clearly illustrated by the differential detergent resistance of the three ras isoforms, $\mathrm{H}$-, $\mathrm{N}$-, and K-Ras (Figure 3A). In an elegant set of experiments combining detergent resistance, nondetergent fractionation, antibody patching, and electron microscopy, it was shown that the doubly palmitoylated H-Ras was raft associated, whereas the nonpalmitoylated isoform (K-Ras) was excluded from these PM microdomains $(112,113)$. Importantly, H-Ras was only raftresident when in the GDP-loaded inactive state, while activation by GTP led to expulsion from rafts that was required for activation of its downstream kinase raf (Figure 3C). Additionally, as is the case for G-proteins, the trafficking of H-Ras is strongly dependent on palmitoylation and raft localization (114) (and reviewed in refs 115 and 116). Palmitoylated (raft associated) H-Ras is trafficked from the Golgi to the PM, where depalmitoylation (loss of raft association) targets it for return to the Golgi (where repalmitoylation occurs), while signaling is maintained at both locations (117) (Figure 3B). Additionally, recent experiments suggest that the two palmitoylation sites serve distinct roles in both trafficking and GTP-dependent raft-targeting of H-Ras (118), emphasizing that though palmitoylation appears to be an important determinant of raft association and activity regulation, the story does not end there and signaling regulation of this important class of proteins is likely accomplished by several independent and well-regulated mechanisms.

Palmitoylation, Rafts, and Disease. There are several disease states associated with proper protein palmitoylation where improper raft partitioning of the modified protein may be related to the etiology of the disease. An important subtype of these is oncogenic transformation mediated by aberrant signaling either through the Ras (119) or Src (120) family of proteins. Additionally, palmitoylation has an extensively characterized role in neuronal function and development (reviewed in ref 121), while misregulation of protein palmitoylation has been observed to lead to neurological disorders (122-124). These effects may be mediated by proteins such as GAP-43 (125) and PSD-95 (126), which require palmitoylation for interaction between the neuronal plasma membrane and the cytoskeletal cortex to allow the proper morphological remodeling necessary to neuronal function, in analogy to the role of palmitoylated stomatin in erythrocytes (127). Another instance of the possible involvement of palmitoylation-dependent raft localization in neuropathogenesis is Alzheimer's disease. Palmitoylation is necessary for raft association of the $\beta$-secretase (BACE) that generates the plaque forming $\mathrm{A} \beta$ peptide thought to be involved in disease progression, and this domain partitioning has been proposed to be important for BACE activity (reviewed in ref 128), though this link remains inconclusive (129). An exciting potential direction in the treatment of this disease, and potentially others whose pathogenesis requires raft association, is the synthesis of raft-targeting inhibitor compounds whose reduced dimensionality (i.e., two-dimensional rather than three-dimensional diffusion) and subcompartmental targeting greatly enhance their efficiency (130).

\section{THE MANY FACES OF PALMITOYLATION- DEPENDENT RAFT ASSOCIATION}

Only some of the cellular mechanisms relying on palmitoylation for proper raft association have been discussed at length here, while several others have been investigated and wellcharacterized. For example, the extensive role of palmitoylation in axonal targeting and neuronal development was reviewed in by El-Husseini and Brendt (121). Also, it was recently discovered that palmitoylation was required for efficient apoptotic signaling through both the Fas (131) and TRAIL receptors (132). Finally, the role of lipid rafts in the regulation and compartmentalization of palmitoylated endothelial nitric oxide synthase and other enzymes involved in redox signaling has been documented (reviewed in ref 133).

Palmitoylation of TM Proteins in Raft Targeting: Necessary but Not Sufficient? It is important to emphasize that while palmitoylation is almost certainly important and possibly even necessary for most TM protein partitioning into ordered membrane domains, it is neither sufficient nor absolutely required (Figure 4). Numerous studies on the TM domain requirements for raft partitioning have demonstrated that residues interacting with the exoplasmic leaflet are required for detergent insolubility $(72,86)$ and raft partitioning $(87)$ of palmitoylated proteins. Additionally, there are many known palmitoylated proteins that are not believed to be associated with membrane rafts, including the canonical marker of nonraft membranes, the transferrin receptor (134) and the spike glycoprotein in vesicular stomatitis virus, VSVG (135). For several raft-associated palmitoylated proteins, the modification seems to be redundant, as is the case for the canonical raft protein caveolin, which is multiply palmitoylated, but remains detergent-resistant when the palmitoylated cysteines are mutated (136). Finally, a recent report suggests that while palmitoylation is required for detergent resistance of the anthrax toxin, it actually inhibits the raft association of its receptor (137).

While the general principle of raft targeting by modification with saturated fatty acids appears to hold for a number of protein involved in a great variety of important signaling pathways, it is neither always applicable nor sufficient to explain the submembrane compartmentalization of the many proteins modified in this way. The chemical nature of the transmembrane polypeptide has already been shown to be important for DRM association and apical trafficking $(72,138)$, although the molecular details of these determinants remain unclear.

\section{RAFT TARGETING IN PARACRINE SIGNALING - CHOLESTEROL MODIFICATION OF HEDGEHOG}

A unique lipid modification has been described to potentially target extracellularly secreted morphogens to membrane rafts as a component of paracrine signaling. The Hedgehog $(\mathrm{Hh})$ family of proteins regulates spatial patterning in animals from insects 


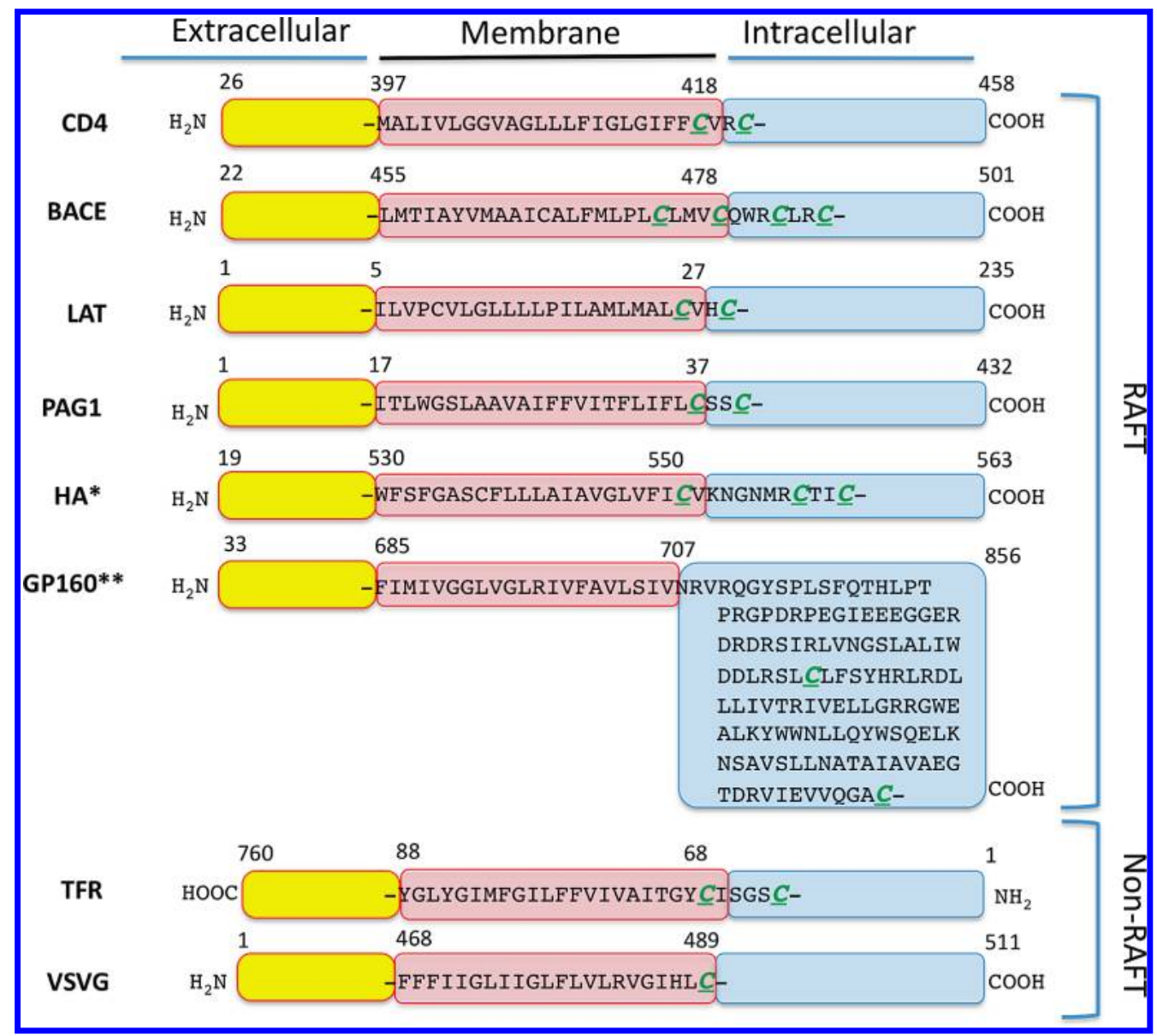

FIgURe 4: Palmitoylation of transmembrane proteins does not guarantee their association with membrane rafts. Examples of known palmitoylated single-span membrane proteins, which either do or do not associate with rafts. For the raft associated proteins at least double palmitoylation seems to be a prerequisite for raft partitioning. Palmitoyl-modified cysteines may be part of the transmembrane region, lie at the membrane interface, or in proximity to the transmembrane fragment and the palmitoyl groups are attached on Cys residues that are close to each other $(n+2)$. However, there are some exceptions, for example, in GP160 the lipid modified Cys residues are separated from each other in the sequence and are not membrane proximal. For the nonraft palmitoylated proteins these are either monopalmitoylated (VSVG) or as observed for the TFR the acyl-modified Cys are separated by four residues. *HA - H7N1- Fowl plague virus/Rostock/8/1934; **GP160 $\mathrm{HV} 1 \mathrm{H} 2$ strain.

to mammals. During synthesis, Hh undergoes autocatalytic cleavage that adds a cholesterol moiety to the carboxy-terminal glycine of the signaling-active $\mathrm{N}$-terminal $\mathrm{Hh}$ fragment (139) (this study also observed sterol modification of other proteins, but these have yet to be identified so the Hedgehog family remains the only known sterolated protein). It was found that this modification confers detergent resistance (140), suggesting its inclusion in raft domains where it presumably associates with its detergentresistant receptor, Patched (141). In addition to its C-terminal sterolation, Hh is modified with the saturated palmitic acid on its $\mathrm{N}$-terminal cysteine (142), although it is important to note that the mechanism and enzymology of this palmitoylation is very different from palmitoylation of intracellular proteins, which generally have the fatty acid linked through an S-linked thioester, rather than Hh's N-linked amide (143). Palmitoylation was also observed to be required for the function of several other important secreted signaling molecules, including Spitz (the epidermal growth factor homologue in flies) (144) and wingless (Wnt) (145), which was found to be detergent resistant (146). In the case of $\mathrm{Hh}$, both sterol modification (147) and palmitoylation (148) were required for the formation of high molecular weight complexes necessary for efficient signaling. The most recent model of $\mathrm{Hh}$ signaling is that its long-range diffusion is mediated by transport on plasma lipoproteins (149), and whether raft domains are involved in this process remains to be studied.

\section{POLYUNSATURATED AND BRANCHED FATTY ACIDS - NONRAFT ASSOCIATING LIPIDATIONS}

While the case for GPI-anchors and palmitoylations targeting proteins to raft domains is strong, it is not without exceptions. On the other hand, the data appears largely consistent that modification of proteins with branched and/or unsaturated fatty acids strongly restricts them from association with lipid rafts. The strongest evidence for this assertion comes from studies where normally saturated fatty acid modifications were replaced with polyunsaturated fatty acids (PUFAs) by exogenous metabolic labeling. In this set of experiments, it was shown that the incorporation of both monounsaturated and especially PUFAs into the normal S-acylation sites of Fyn and LAT significantly reduced the association of these normally raft-resident molecules with detergent resistant fractions (48). Importantly, loss of raft localization led to signaling changes, as PUFA-incorporating T-cells were deficient in kinase activity downstream of activation of the T-cell receptor, both confirming the role of raftassociation in immune system signaling and suggesting a mechanism for the immunosuppressive effects of PUFAs $(47,150)$. 
Similar effects were observed for the Gag protein of HIV-1, which lost both raft association and the ability to mediate viral particle assembly upon modification with unsaturated fatty acids (151), and the $\alpha$ subunit of a heterotrimeric $\mathrm{G}_{\mathrm{i}}$ protein (102).

A similar role was observed for protein prenylation, which involves the addition of a branched, unsaturated isoprenyl group as a thioether to free intracellular cysteines. These usually take the form of $15-\mathrm{C}$ or 20-C aliphatic chains (farnesyl and geranylgeranyl, respectively) added to the protein cotranslationally, which remain with the protein until it is degraded (reviewed in ref 152). Proteins carrying this modification were found to be constitutively excluded from DRMs, in line with the expected difficulty of packing these branched, bulky hydrocarbons into the ordered environment of a lipid raft (82). In vitro reconstitution and lack of detergent-resistance of the farnesylated $\beta \gamma$ subunits of a heterotrimeric G-protein confirmed this result (153). This observation was extended by a high-resolution study of clustering of lipid anchored fluorescent proteins which showed that model proteins bound to the membrane by isoprenyl (and myristoyl) anchors were less clustered in undisturbed plasma membranes than palmitoylated (presumably raft localized) ones (154). This general principle is illustrated best by a specific example: the differential raft affinity of Ras isoforms. Whereas palmitoylated versions of the protein (especially the doubly acylated H-Ras discussed above) are strongly raft-localized, the prenylated $\mathrm{K}-\mathrm{Ras} 4 \mathrm{~B}$ is generally excluded regardless of activation state (113), despite strong sequence similarities. The multiple different lipidations of these important signaling molecules generate an exciting hypothesis: that proteins (specifically $\mathrm{H}-$ and $\mathrm{N}$-Ras) modified with neighboring lipid modifications of different raft affinities (e.g., prenylation and palmitoylation) would preferentially target to the edges of raft domains and behave as lineactants (twodimensional analogues of surfactants) to stabilize these rafts (155). Clear data supporting this possibility has yet to emerge, although recent findings using high-resolution spatial detection suggest that $\mathrm{N}$-ras does localize to raft boundaries and perhaps stabilizes the domains by decreasing the interfacial energy between the domains and the bulk lipid phase $(156,157)$.

An important cotranslational lipid modification that has not been discussed in detail in this review is N-terminal myristoylation, the addition of a $\mathrm{C} 14$ saturated acyl chain to the $\mathrm{N}$-terminal glycine of several proteins, typically those without a TM polypeptide (reviewed in ref 158 ). Generally speaking, a single myristate is not enough to direct the modified protein to a raft domain and another, longer, saturated acylation is required. This is the case for c-Src (159) and Blk (120) in comparison to several homologous, palmitoylated SFKs (110), and the DRM partitioning of these homologues has been recently implicated in their transforming capacity (120). However, the data implicating myristolation as an obligate nonraft targeter are not entirely consistent as c-Src was also found in DRMs isolated from a neuronal cell line (160), although these results must be evaluated with a consideration to possible detergent resistance artifacts. Additionally, the myristoylated neuronal protein NAP-22 is targeted to ordered domains in model monolayers (161), although its cholesterol binding capacity is likely important for this function.

\section{PERSPECTIVES}

Post-translational lipid modifications are critical regulators of affinity for membrane domains for both soluble and membrane embedded proteins, with the general paradigm being long $(\geq \mathrm{C} 16)$, saturated acyl chains (i.e., GPI-anchors and palmitoylations in the extracellular and intracellular leaflet, respectively) conferring raft affinity while unsaturated, short, and branched lipidic moieties prevent raft association. While these principles appear to be generally applicable, many outstanding issues remain regarding the specific regulatory functions of particular protein modifications.

For example, palmitoylation is not sufficient for raft partitioning of TM proteins, so the other determinants of raft affinity remain to be fully characterized. One clear feature is that mutation of bulky hydrophobic residues in the exoplasmic leaflet-interfacing part of the TMD of the HA spike glycoprotein of influenza strongly inhibit raft partitioning $(72,86,87)$. The specific residues important for this requirement and the underlying physical mechanisms are currently unknown. Similarly, the function of heterologous S-acylation with saturated fatty acids longer than palmitic (e.g., such as stearic acid $(84,162))$ and the effect of their location in the protein relative to the PM have yet to be identified and are likely to play important roles in determining the raft affinity of modified proteins (see Figure 4).

In addition to the raft-regulatory function of palmitoylation on individual proteins, important general questions remain regarding spatial and temporal regulation of protein palmitoylation in general. The data presented above suggest that this regulation will likely prove an important mechanism for control of raft-related signaling pathways. Although recent studies have begun to address some of these questions (reviewed in refs 163-165), a lack of a suitable experimental framework currently limits investigation. The most specific limitation is that while several methods exist to determine which proteins are palmitoylated (e.g., metabolic labeling of cells with radioactive palmitate and acyl-biotinyl exchange (41)), these are generally not quantitative, nor do they allow determination of the fraction of palmitoylated protein. An exciting potential direction in this field would be the development of lipid modification-specific antibodies which can be used to quantify ratios of lipidated-tounmodified protein and begin to address outstanding issues of the location and regulation of protein palmitoylation.

Definitive quantification of lipid-dependent phase partitioning can be achieved using model systems that incorporate labeled proteins of interest. Phase separation in synthetic GUVs (32) and cell-derived PMS (38) and GPMVs $(37,166)$ comprise a novel experimental framework for direct quantification of membrane protein partitioning between coexistent liquid phases. While saturated lipid anchored proteins have been shown to partition to raft domains across the model systems $(33,36,38,161,167)$, few if any transmembrane proteins have been observed to prefer the tightly packed environment of the ordered phase in GUVs and GPMVs $(34,36,39,167,168)$, in contrast to strong enrichment of TM raft components in the raft phase of PMS. Although this discrepancy remains to be clarified, it may involve loss of relatively labile thiol-linked palmitates during protein isolation or purification. An additional limitation of these experimental model systems is the loss of the asymmetric lipid composition that is characteristic of the eukaryotic plasma membrane and the effect of this asymmetry on coupling of raft domains across the two leaflets of the lipid bilayer $(20,30,169)$. Several novel techniques have been developed to produce asymmetric membranes $(95,170,171)$, however the mechanisms of induction of raft domains in the cytoplasmic leaflet of the PM (172) and coupling of peripheral signaling proteins across the bilayer remain unexplained. 
Other outstanding issues include, for example, heterogeneity of GPI-anchors (e.g., addition of a third acyl chain to the inositol backbone (173)), their role in regulating domain preference, and the regulation/specificity of this heterogeneity. Additionally, incorporation of PUFAs as modifications into proteins, and their subsequent exclusion from raft domains, remains a largely unexplored topic. To summarize, despite a significant amount of research and insight into the role of protein lipidation in targeting to different membrane domains, many specific and general questions remain in this active and thriving field. The introduction of novel methods such as the preparation of intact cellular membranes and high resolution microscopy and particle tracking promises to unlock the details of a layer of regulation likely to play a critical role in cellular signaling.

\section{REFERENCES}

1. Stevens, T. J., and Arkin, I. T. (2000) Do more complex organisms have a greater proportion of membrane proteins in their genomes? Proteins 39, 417-420.

2. Lingwood, D., Simons, K. Lipid rafts as a membrane-organizing principle. Science 327, 46-50.

3. Chatterjee, S., and Mayor, S. (2001) The GPI-anchor and protein sorting. Cell. Mol. Life Sci. 58, 1969-1987.

4. Fujita, M., and Kinoshita, T. (2009) Structural remodeling of GPI anchors during biosynthesis and after attachment to proteins. FEBS Lett. 584, 1670-1677.

5. Ferguson, M. A. J., Kinoshita, T., Hart, G. W. (2009) Glycosylphosphatidylinositol Anchors, in Essentials of Glycobiology (Varki, A., Cummings, R. D., Esko, J. D., Freeze, H. H., Hart, G. W., Etzler, M. E., Eds.) 2nd ed., Cold Spring Harbor Laboratory Press, Cold Spring Harbor, NY.

6. Brown, D. A., and Rose, J. K. (1992) Sorting of GPI-anchored proteins to glycolipid-enriched membrane subdomains during transport to the apical cell surface. Cell 68, 533-544.

7. Fiedler, K., Kobayashi, T., Kurzchalia, T. V., and Simons, K. (1993) Glycosphingolipid-enriched, detergent-insoluble complexes in protein sorting in epithelial cells. Biochemistrv 32, 6365-6373.

8. Lisanti, M. P., Sargiacomo, M., Graeve, L., Saltiel, A. R., and Rodriguez-Boulan, E. (1988) Polarized apical distribution of glycosyl-phosphatidylinositol-anchored proteins in a renal epithelial cell line. Proc. Natl. Acad. Sci. U. S. A. 85, 9557-9561.

9. Lisanti, M. P., Le Bivic, A., Saltiel, A. R., and Rodriguez-Boulan, E. (1990) Preferred apical distribution of glycosyl-phosphatidylinositol (GPI) anchored proteins: a highly conserved feature of the polarized epithelial cell phenotype. J. Membr. Biol. 113, 155-167.

10. Lisanti, M. P., Caras, I. W., Davitz, M. A., and Rodriguez-Boulan, E. (1989) A glycophospholipid membrane anchor acts as an apical targeting signal in polarized epithelial cells. J. Cell Biol. 109, 2145-2156.

11. Esfahani, M., Bigler, R. D., Alfieri, J. L., Lund-Katz, S., Baum, J. D., and Scerbo, L. (1993) Cholesterol regulates the cell surface expression of glycophospholipid-anchored CD14 antigen on human monocytes. Biochim. Biophvs. Acta 1149, 217-223.

12. Hanada, K., Nishijima, M., Akamatsu, Y., and Pagano, R. E. (1995) Both sphingolipids and cholesterol participate in the detergent insolubility of alkaline phosphatase, a glycosylphosphatidylinositol-anchored protein, in mammalian membranes. J. Biol. Chem. 270, 6254-6260.

13. Schroeder, R. J., Ahmed, S. N., Zhu, Y., London, E., and Brown, D. A. (1998) Cholesterol and sphingolipid enhance the Triton X-100 insolubility of glycosylphosphatidylinositol-anchored proteins by promoting the formation of detergent-insoluble ordered membrane domains. J. Biol. Chem. 273, 1150-1157.

14. Benting, J., Rietveld, A., Ansorge, I., and Simons, K. (1999) Acyl and alkyl chain length of GPI-anchors is critical for raft association in vitro. FEBS Lett. 462, 47-50.

15. Schuck, S., Honsho, M., Ekroos, K., Shevchenko, A., and Simons, K. (2003) Resistance of cell membranes to different detergents. Proc. Natl. Acad. Sci. U. S. A. 100, 5795-5800.

16. Heerklotz, H. (2002) Triton promotes domain formation in lipid raft mixtures. Biophvs. J. 83, 2693-2701.

17. Lingwood, D., and Simons, K. (2010) Lipid rafts as a membraneorganizing principle. Science $327,46-50$

18. Coskun, U., Simons, K. (2009) Membrane rafting: From apical sorting to phase segregation. FEBS Lett. 584, 1685-1693.
19. Spiegel, S., Kassis, S., Wilchek, M., and Fishman, P. H. (1984) Direct visualization of redistribution and capping of fluorescent gangliosides on lymphocytes. J. Cell Biol. 99, 1575-1581.

20. Harder, T., Scheiffele, P., Verkade, P., and Simons, K. (1998) Lipid domain structure of the plasma membrane revealed by patching of membrane components. J. Cell Biol. 141, 929-942.

21. Harder, T., and Simons, K. (1999) Clusters of glycolipid and glycosylphosphatidylinositol-anchored proteins in lymphoid cells: accumulation of actin regulated by local tyrosine phosphorylation. Eur. J. Immunol. 29, 556-562.

22. Manes, S., and Viola, A. (2006) Lipid rafts in lymphocyte activation and migration. Mol. Membr. Biol. 23, 59-69.

23. Varma, R., and Mayor, S. (1998) GPI-anchored proteins are organized in submicron domains at the cell surface. Nature 394, 798-801.

24. Sharma, P., Varma, R., Sarasij, R. C., Ira, S., Gousset, K., Krishnamoorthy, G., Rao, M., and Mayor, S. (2004) Nanoscale organization of multiple GPI-anchored proteins in living cell membranes. Cell 116, 577-589.

25. Friedrichson, T., and Kurzchalia, T. V. (1998) Microdomains of GPI-anchored proteins in living cells revealed by crosslinking. Nature 394, 802-805.

26. van Zanten, T. S., Cambi, A., Koopman, M., Joosten, B., Figdor, C. G., and Garcia-Parajo, M. F. (2009) Hotspots of GPI-anchored proteins and integrin nanoclusters function as nucleation sites for cell adhesion. Proc. Natl. Acad. Sci. U. S. A. 106, 18557-18562.

27. Sheets, E. D., Lee, G. M., Simson, R., and Jacobson, K. (1997) Transient confinement of a glycosylphosphatidylinositol-anchored protein in the plasma membrane. Biochemistry 36, 12449-12458.

28. Suzuki, K. G., Fujiwara, T. K., Sanematsu, F., Iino, R., Edidin, M., and Kusumi, A. (2007) GPI-anchored receptor clusters transiently recruit Lyn and G alpha for temporary cluster immobilization and Lyn activation: single-molecule tracking study 1. J. Cell Biol. 177, 717-730.

29. Murase, K., Fujiwara, T., Umemura, Y., Suzuki, K., Iino, R., Yamashita, H., Saito, M., Murakoshi, H., Ritchie, K., and Kusumi, A. (2004) Ultrafine membrane compartments for molecular diffusion as revealed by single molecule techniques. Biophvs. J. 86 , 4075-4093.

30. Suzuki, K. G., Fujiwara, T. K., Edidin, M., and Kusumi, A. (2007) Dynamic recruitment of phospholipase $\mathrm{C}$ gamma at transiently immobilized GPI-anchored receptor clusters induces IP3-Ca2+ signaling: single-molecule tracking study 2. J. Cell Biol. 177, 731-742.

31. Kusumi, A., Nakada, C., Ritchie, K., Murase, K., Suzuki, K., Murakoshi, H., Kasai, R. S., Kondo, J., and Fujiwara, T. (2005) Paradigm shift of the plasma membrane concept from the twodimensional continuum fluid to the partitioned fluid: high-speed single-molecule tracking of membrane molecules. Annu. Rev. Biophvs. Biomol. Struct. 34, 351-378.

32. Veatch, S. L., and Keller, S. L. (2003) Separation of liquid phases in giant vesicles of ternary mixtures of phospholipids and cholesterol. Biophvs. J. 85, 3074-3083.

33. Dietrich, C., Volovyk, Z. N., Levi, M., Thompson, N. L., and Jacobson, K. (2001) Partitioning of Thy-1, GM1, and cross-linked phospholipid analogs into lipid rafts reconstituted in supported model membrane monolayers. Proc. Natl. Acad. Sci. U. S. A. 98, 10642-10647.

34. Kahya, N., Brown, D. A., and Schwille, P. (2005) Raft partitioning and dynamic behavior of human placental alkaline phosphatase in giant unilamellar vesicles. Biochemistrv 44, 7479-7489.

35. Kaiser, H. J., Lingwood, D., Levental, I., Sampaio, J. L., Kalvodova, L., Rajendran, L., and Simons, K. (2009) Order of lipid phases in model and plasma membranes. Proc. Natl. Acad. Sci. U. S. A. 106, 16645-16650.

36. Sengupta, P., Hammond, A., Holowka, D., and Baird, B. (2008) Structural determinants for partitioning of lipids and proteins between coexisting fluid phases in giant plasma membrane vesicles. Biochim. Biophvs. Acta 1778, 20-32.

37. Baumgart, T., Hammond, A. T., Sengupta, P., Hess, S. T., Holowka, D. A., Baird, B. A., and Webb, W. W. (2007) Large-scale fluid/fluid phase separation of proteins and lipids in giant plasma membrane vesicles. Proc. Natl. Acad. Sci. U. S. A. 104, 3165-3170.

38. Lingwood, D., Ries, J., Schwille, P., and Simons, K. (2008) Plasma membranes are poised for activation of raft phase coalescence at physiological temperature. Proc. Natl. Acad. Sci. U. S. A. 105, 10005-10010.

39. Johnson, S. A., Stinson, B. M., Go, M., Carmona, L. M., Reminick, J. I., Fang, X., and Baumgart, T. (2010) Temperature-dependent phase behavior and protein partitioning in giant plasma membrane vesicles. Biochim. Biophvs. Acta 1798, 1427-1435. 
40. Kang, R., Wan, J., Arstikaitis, P., Takahashi, H., Huang, K., Bailey, A. O., Thompson, J. X., Roth, A. F., Drisdel, R. C., Mastro, R., Green, W. N., Yates, J. R., 3rd, Davis, N. G., and El-Husseini, A. (2008) Neural palmitoyl-proteomics reveals dynamic synaptic palmitoylation. Nature 456, 904-909.

41. Wan, J., Roth, A. F., Bailey, A. O., and Davis, N. G. (2007) Palmitoylated proteins: purification and identification. Nat. Protoc. 2, 1573-1584.

42. Roth, A. F., Wan, J., Bailey, A. O., Sun, B., Kuchar, J. A., Green, W. N., Phinney, B. S., Yates, J. R., 3rd, and Davis, N. G. (2006) Global analysis of protein palmitoylation in yeast. Cell 125, 1003-1013.

43. He, H. T., Lellouch, A., and Marguet, D. (2005) Lipid rafts and the initiation of T cell receptor signaling. Semin. Immunol. 17, 23-33.

44. Harder, T. (2004) Lipid raft domains and protein networks in T-cell receptor signal transduction. Curr. Opin. Immunol. 16, 353-359.

45. Rodgers, W., Crise, B., and Rose, J. K. (1994) Signals determining protein tyrosine kinase and glycosyl-phosphatidylinositol-anchored protein targeting to a glycolipid-enriched membrane fraction. $\underline{\mathrm{Mol}}$. Cell. Biol. 14, 5384-5391.

46. Arni, S., Ilangumaran, S., van Echten-Deckert, G., Sandhoff, K., Poincelet, M., Briol, A., Rungger-Brandle, E., and Hoessli, D. C. (1996) Differential regulation of Src-family protein tyrosine kinases in GPI domains of T lymphocyte plasma membranes. Biochem. Biophvs. Res. Commun. 225, 801-807.

47. Webb, Y., Hermida-Matsumoto, L., and Resh, M. D. (2000) Inhibition of protein palmitoylation, raft localization, and $\mathrm{T}$ cell signaling by 2-bromopalmitate and polyunsaturated fatty acids. J. Biol. Chem. 275, 261-270.

48. Liang, X., Nazarian, A., Erdjument-Bromage, H., Bornmann, W., Tempst, P., and Resh, M. D. (2001) Heterogeneous fatty acylation of Src family kinases with polyunsaturated fatty acids regulates raft localization and signal transduction. J. Biol. Chem. 276, 3098730994.

49. Parolini, I., Sargiacomo, M., Lisanti, M. P., and Peschle, C. (1996) Signal transduction and glycophosphatidylinositol-linked proteins (lyn, lck, CD4, CD45, G proteins, and CD55) selectively localize in Triton-insoluble plasma membrane domains of human leukemic cell lines and normal granulocytes. Blood 87, 3783-3794.

50. Cerny, J., Stockinger, H., and Horejsi, V. (1996) Noncovalent associations of $\mathrm{T}$ lymphocyte surface proteins. Eur. J. Immunol. $26,2335-2343$.

51. Fragoso, R., Ren, D., Zhang, X., Su, M. W., Burakoff, S. J., and Jin, Y.-J. (2003) Lipid raft distribution of CD4 depends on its palmitoylation and association with Lck, and evidence for CD4-induced lipid raft aggregation as an additional mechanism to enhance CD3 signaling. J. Immunol. 170, 913-921.

52. Balamuth, F., Brogdon, J. L., and Bottomly, K. (2004) CD4 raft association and signaling regulate molecular clustering at the immunological synapse site. J. Immunol. 172, 5887-5892.

53. Arcaro, A., Gregoire, C., Boucheron, N., Stotz, S., Palmer, E., Malissen, B., and Luescher, I. F. (2000) Essential role of CD8 palmitoylation in CD8 coreceptor function. J. Immunol. 165, 2068-2076.

54. Popik, W., and Alce, T. M. (2004) CD4 receptor localized to non-raft membrane microdomains supports HIV-1 entry. Identification of a novel raft localization marker in CD4. J. Biol. Chem. 279, 704-712.

55. Filipp, D., Moemeni, B., Ferzoco, A., Kathirkamathamby, K., Zhang, J., Ballek, O., Davidson, D., Veillette, A., and Julius, M. (2008) Lck-dependent Fyn activation requires $\mathrm{C}$ terminus-dependent targeting of kinase-active Lck to lipid rafts. J. Biol. Chem. 283, 26409-26422.

56. Resh, M. D. (2006) Palmitoylation of ligands, receptors, and intracellular signaling molecules. Sci. STKE 2006, re14.

57. Zhang, W., Sloan-Lancaster, J., Kitchen, J., Trible, R. P., and Samelson, L. E. (1998) LAT: the ZAP-70 tyrosine kinase substrate that links $\mathrm{T}$ cell receptor to cellular activation. Cell 92, 83-92.

58. Harder, T., and Kuhn, M. (2000) Selective accumulation of raftassociated membrane protein LAT in $\mathrm{T}$ cell receptor signaling assemblies. J. Cell Biol. 151, 199-208.

59. Zhang, W., Trible, R. P., and Samelson, L. E. (1998) LAT palmitoylation: its essential role in membrane microdomain targeting and tyrosine phosphorylation during T cell activation. Immunity 9, 239-246.

60. Hundt, M., Tabata, H., Jeon, M. S., Hayashi, K., Tanaka, Y., Krishna, R., De Giorgio, L., Liu, Y. C., Fukata, M., and Altman, A. (2006) Impaired activation and localization of LAT in anergic T cells as a consequence of a selective palmitoylation defect. Immunity 24, $513-522$.

61. Hundt, M., Harada, Y., De Giorgio, L., Tanimura, N., Zhang, W., and Altman, A. (2009) Palmitoylation-dependent plasma membrane transport but lipid raft-independent signaling by linker for activation of T cells. J. Immunol. 183, 1685-1694.

62. Zhu, M., Shen, S., Liu, Y., Granillo, O., and Zhang, W. (2005) Cutting Edge: Localization of linker for activation of T cells to lipid rafts is not essential in $\mathrm{T}$ cell activation and development. J. Immunol. 174, 31-35.

63. Otahal, P., Angelisova, P., Hrdinka, M., Brdicka, T., Novak, P., Drbal, K., and Horejsi, V. (2010) A new type of membrane raft-like microdomains and their possible involvement in TCR signaling. J. Immunol. 184, 3689-3696.

64. Kwiatkowska, K., Frey, J., and Sobota, A. (2003) Phosphorylation of FcgammaRIIA is required for the receptor-induced actin rearrangement and capping: the role of membrane rafts. J. Cell Sci. 116, $537-550$.

65. Barnes, N. C., Powell, M. S., Trist, H. M., Gavin, A. L., Wines, B. D., and Hogarth, P. M. (2006) Raft localisation of FcgammaRIIa and efficient signaling are dependent on palmitoylation of cysteine 208. Immunol. Lett. 104, 118-123.

66. Munro, S. (2003) Lipid rafts: elusive or illusive? Cell 115, 377-388.

67. Kenworthy, A. K. (2008) Have we become overly reliant on lipid rafts? Talking Point on the involvement of lipid rafts in T-cell activation. EMBO Rep. 9, 531-535.

68. Lingwood, D., and Simons, K. (2007) Detergent resistance as a tool in membrane research. Nat. Protoc. 2, 2159-2165.

69. Lichtenberg, D., Goni, F. M., and Heerklotz, H. (2005) Detergentresistant membranes should not be identified with membrane rafts. Trends Biochem. Sci. 30, 430.

70. Zech, T., Ejsing, C. S., Gaus, K., de Wet, B., Shevchenko, A., Simons, K., and Harder, T. (2009) Accumulation of raft lipids in T-cell plasma membrane domains engaged in TCR signalling. EMBO J. 28, 466-476.

71. Shogomori, H., Hammond, A. T., Ostermeyer-Fay, A. G., Barr, D. J., Feigenson, G. W., London, E., and Brown, D. A. (2005) Palmitoylation and intracellular domain interactions both contribute to raft targeting of linker for activation of T cells. J. Biol. Chem. 280, 18931-18942.

72. Scheiffele, P., Roth, M. G., and Simons, K. (1997) Interaction of influenza virus haemagglutinin with sphingolipid-cholesterol membrane domains via its transmembrane domain. EMBO J. 16, $5501-5508$

73. Campbell, S. M., Crowe, S. M., and Mak, J. (2001) Lipid rafts and HIV-1: from viral entry to assembly of progeny virions. J.Clin. Virol. $22,217-227$

74. Manie, S. N., de Breyne, S., Vincent, S., and Gerlier, D. (2000) Measles virus structural components are enriched into lipid raft microdomains: a potential cellular location for virus assembly. J. Virol. 74, 305-311.

75. Bavari, S., Bosio, C. M., Wiegand, E., Ruthel, G., Will, A. B., Geisbert, T. W., Hevey, M., Schmaljohn, C., Schmaljohn, A., and Aman, M. J. (2002) Lipid raft microdomains: a gateway for compartmentalized trafficking of ebola and marburg viruses. J. Exp. Med. 195, 593-602.

76. Ochsenbauer-Jambor, C., Miller, D. C., Roberts, C. R., Rhee, S. S., and Hunter, E. (2001) Palmitoylation of the Rous sarcoma virus transmembrane glycoprotein is required for protein stability and virus infectivity. J. Virol. 75, 11544-11554.

77. Manes, S., del Real, G., and Martinez, A. C. (2003) Pathogens: raft hijackers. Nat. Rev. Immunol. 3, 557-568.

78. Chazal, N., and Gerlier, D. (2003) Virus entry, assembly, budding, and membrane rafts. Microbiol. Mol. Biol. Rev. 67, 226-237.

79. Kundu, A., Avalos, R. T., Sanderson, C. M., and Nayak, D. P. (1996) Transmembrane domain of influenza virus neuraminidase, a type II protein, possesses an apical sorting signal in polarized MDCK cells. J. Virol. 70, 6508-6515.

80. Scheiffele, P., Rietveld, A., Wilk, T., and Simons, K. (1999) Influenza viruses select ordered lipid domains during budding from the plasma membrane. J. Biol. Chem. 274, 2038-2044.

81. Nobusawa, E., Aoyama, T., Kato, H., Suzuki, Y., Tateno, Y., and Nakajima, K. (1991) Comparison of complete amino acid sequences and receptor-binding properties among 13 serotypes of hemagglutinins of influenza A viruses. Virology 182, 475-485.

82. Melkonian, K. A., Ostermeyer, A. G., Chen, J. Z., Roth, M. G., and Brown, D. A. (1999) Role of lipid modifications in targeting proteins to detergent-resistant membrane rafts. Many raft proteins are acylated, while few are prenylated. J. Biol. Chem. 274, 3910-3917.

83. Chen, B. J., Takeda, M., and Lamb, R. A. (2005) Influenza virus hemagglutinin ( $\mathrm{H} 3$ subtype) requires palmitoylation of its cytoplasmic tail for assembly: M1 proteins of two subtypes differ in their ability to support assembly. J. Virol. 79, 13673-13684. 
84. Kordyukova, L. V., Serebryakova, M. V., Baratova, L. A., and Veit, M. (2008) S acylation of the hemagglutinin of influenza viruses: mass spectrometry reveals site-specific attachment of stearic acid to a transmembrane cysteine. J. Virol. 82, 9288-9292.

85. Kordyukova, L. V., Serebryakova, M. V., Baratova, L. A., and Veit, M. (2008) Site-specific attachment of palmitate or stearate to cytoplasmic versus transmembrane cysteines is a common feature of viral spike proteins. Virologv 398, 49-56.

86. Takeda, M., Leser, G. P., Russell, C. J., and Lamb, R. A. (2003) Influenza virus hemagglutinin concentrates in lipid raft microdomains for efficient viral fusion. Proc. Natl. Acad. Sci. U. S. A. 100, 14610-14617.

87. Engel, S., Scolari, S., Thaa, B., Krebs, N., Korte, T., Herrmann, A., and Veit, M. (2010) FLIM-FRET and FRAP reveal association of influenza virus haemagglutinin with membrane rafts. Biochem. $J$ $425,567-573$.

88. Rousso, I., Mixon, M. B., Chen, B. K., and Kim, P. S. (2000) Palmitoylation of the HIV-1 envelope glycoprotein is critical for viral infectivity. Proc. Natl. Acad. Sci. U. S. A. 97, 13523-13525.

89. Nguyen, D. H., and Hildreth, J. E. (2000) Evidence for budding of human immunodeficiency virus type 1 selectively from glycolipidenriched membrane lipid rafts. J. Virol. 74, 3264-3272.

90. Manes, S., del Real, G., Lacalle, R. A., Lucas, P., Gomez-Mouton, C., Sanchez-Palomino, S., Delgado, R., Alcami, J., Mira, E., and Martinez, A. C. (2000) Membrane raft microdomains mediate lateral assemblies required for HIV-1 infection. EMBO Rep. 1, 190-196.

91. Kuhmann, S. E., Platt, E. J., Kozak, S. L., and Kabat, D. (2000) Cooperation of multiple CCR 5 coreceptors is required for infections by human immunodeficiency virus type $1 . \mathrm{J}$. Virol. 74, 7005-7015.

92. Percherancier, Y., Lagane, B., Planchenault, T., Staropoli, I., Altmeyer, R., Virelizier, J. L., Arenzana-Seisdedos, F., Hoessli, D. C., and Bachelerie, F. (2003) HIV-1 entry into T-cells is not dependent on CD4 and CCR5 localization to sphingolipid-enriched, detergentresistant, raft membrane domains. J. Biol. Chem. 278, 3153-3161.

93. del Real, G., Jimenez-Baranda, S., Lacalle, R. A., Mira, E., Lucas, P., Gomez-Mouton, C., Carrera, A. C., Martinez-A, C., and Manes, S. (2002) Blocking of HIV-1 infection by targeting CD4 to nonraft membrane domains. J. Exp. Med. 196, 293-301.

94. Simons, K., and Vaz, W. L. (2004) Model systems, lipid rafts, and cell membranes. Annu. Rev. Biophvs. Biomol. Struct. 33, 269-295.

95. Collins, M. D., and Keller, S. L. (2008) Tuning lipid mixtures to induce or suppress domain formation across leaflets of unsupported asymmetric bilayers. Proc. Natl. Acad. Sci. U. S. A. 105, 124-128.

96. Oh, P., and Schnitzer, J. E. (2001) Segregation of heterotrimeric G proteins in cell surface microdomains. G(q) binds caveolin to concentrate in caveolae, whereas $\mathrm{G}(\mathrm{i})$ and $\mathrm{G}(\mathrm{s})$ target lipid rafts by default. Mol. Biol. Cell 12, 685-698.

97. Prior, I. A., and Hancock, J. F. (2001) Compartmentalization of Ras proteins. J. Cell Sci. 114, 1603-1608.

98. Waheed, A. A., and Jones, T. L. Z. (2002) Hsp90 interactions and acylation target the G Protein Galpha12 but not Galpha13 to lipid rafts. J. Biol. Chem. 277, 32409-32412.

99. Parenti, M., Vigano, M. A., Newman, C. M., Milligan, G., and Magee, A. I. (1993) A novel N-terminal motif for palmitoylation of G-protein alpha subunits. Biochem. J. 291 (Pt 2), 349-353.

100. Koegl, M., Zlatkine, P., Ley, S. C., Courtneidge, S. A., and Magee, A. I. (1994) Palmitoylation of multiple Src-family kinases at a homologous N-terminal motif. Biochem. J. 303 (Pt 3), 749-753.

101. Song, K. S., Sargiacomo, M., Galbiati, F., Parenti, M., and Lisanti, M. P. (1997) Targeting of a G alpha subunit (Gil alpha) and c-Src tyrosine kinase to caveolae membranes: clarifying the role of N-myristoylation. Cell Mol. Biol. 43, 293-303.

102. Moffett, S., Brown, D. A., and Linder, M. E. (2000) Lipid-dependent targeting of $\mathrm{G}$ proteins into rafts. J. Biol. Chem. 275, 2191-2198.

103. Wedegaertner, P. B., and Bourne, H. R. (1994) Activation and depalmitoylation of Gs alpha. Cell 77, 1063-1070.

104. Mumby, S. M., Kleuss, C., and Gilman, A. G. (1994) Receptor regulation of G-protein palmitoylation. Proc. Natl. Acad. Sci.U.S. A. 91, 2800-2804

105. Stanislaus, D., Janovick, J. A., Brothers, S., and Conn, P. M. (1997) Regulation of $\mathrm{G}(\mathrm{q} / 11)$ alpha by the gonadotropin-releasing hormone receptor. Mol. Endocrinol. 11, 738-746.

106. Goswami, R., Ahmed, M., Kilkus, J., Han, T., Dawson, S. A., and Dawson, G. (2005) Differential regulation of ceramide in lipid-rich microdomains (rafts): antagonistic role of palmitoyl:protein thioesterase and neutral sphingomyelinase 2. J. Neurosci. Res. 81, 208-217.

107. Osterhout, J. L., Waheed, A. A., Hiol, A., Ward, R. J., Davey, P. C., Nini, L., Wang, J., Milligan, G., Jones, T. L., and Druey, K. M (2003) Palmitoylation regulates regulator of G-protein signaling
(RGS) 16 function. II. Palmitoylation of a cysteine residue in the RGS box is critical for RGS16 GTPase accelerating activity and regulation of Gi-coupled signalling. J. Biol. Chem. 278, 19309-19316.

108. Michaelson, D., Ahearn, I., Bergo, M., Young, S., and Philips, M. (2002) Membrane trafficking of heterotrimeric $G$ proteins via the endoplasmic reticulum and Golgi. Mol. Biol. Cell 13, 3294-3302.

109. Robbins, S. M., Quintrell, N. A., and Bishop, J. M. (1995) Myristoylation and differential palmitoylation of the HCK proteintyrosine kinases govern their attachment to membranes and association with caveolae. Mol. Cell. Biol. 15, 3507-3515.

110. Shenoy-Scaria, A. M., Dietzen, D. J., Kwong, J., Link, D. C., and Lublin, D. M. (1994) Cysteine3 of Src family protein tyrosine kinase determines palmitoylation and localization in caveolae. J. Cell Biol. 126, 353-363.

111. Brdicka, T., Pavlistova, D., Leo, A., Bruyns, E., Korinek, V., Angelisova, P., Scherer, J., Shevchenko, A., Hilgert, I., Cerny, J., Drbal, K., Kuramitsu, Y., Kornacker, B., Horejsi, V., and Schraven, B. (2000) Phosphoprotein associated with glycosphingolipid-enriched microdomains (PAG), a novel ubiquitously expressed transmembrane adaptor protein, binds the protein tyrosine kinase csk and is involved in regulation of T cell activation. J. Exp. Med. 191, 1591-1604.

112. Prior, I. A., Muncke, C., Parton, R. G., and Hancock, J. F. (2003) Direct visualization of Ras proteins in spatially distinct cell surface microdomains. J. Cell Biol. 160, 165-170.

113. Prior, I. A., Harding, A., Yan, J., Sluimer, J., Parton, R. G., and Hancock, J. F. (2001) GTP-dependent segregation of H-ras from lipid rafts is required for biological activity. Nat. Cell Biol. 3 , $368-375$.

114. Rocks, O., Peyker, A., Kahms, M., Verveer, P. J., Koerner, C., Lumbierres, M., Kuhlmann, J., Waldmann, H., Wittinghofer, A., and Bastiaens, P. I. (2005) An acylation cycle regulates localization and activity of palmitoylated Ras isoforms. Science 307, 1746-1752.

115. Linder, M. E., and Deschenes, R. J. (2007) Palmitoylation: policing protein stability and traffic. Nat. Rev. Mol. Cell Biol. 8, 74-84.

116. Meder, D., and Simons, K. (2005) Ras on the Roundabout. Science 307, 1731-1733.

117. Bivona, T. G., Perez De Castro, I., Ahearn, I. M., Grana, T. M., Chiu, V. K., Lockyer, P. J., Cullen, P. J., Pellicer, A., Cox, A. D., and Philips, M. R. (2003) Phospholipase Cgamma activates Ras on the Golgi apparatus by means of RasGRP1. Nature 424, 694-698.

118. Roy, S., Plowman, S., Rotblat, B., Prior, I. A., Muncke, C., Grainger, S., Parton, R. G., Henis, Y. I., Kloog, Y., and Hancock, J. F. (2005) Individual palmitoyl residues serve distinct roles in H-ras trafficking, microlocalization, and signaling. Mol. Cell. Biol. 25, 6722-6733.

119. Ducker, C. E., Stettler, E. M., French, K. J., Upson, J. J., and Smith, C. D. (2004) Huntingtin interacting protein 14 is an oncogenic human protein: palmitoyl acyltransferase. Oncogene 23, 9230-9237.

120. Oneyama, C., Iino, T., Saito, K., Suzuki, K., Ogawa, A., and Okada, M. (2009) Transforming potential of Src family kinases is limited by the cholesterol-enriched membrane microdomain. Mol. Cell. Biol. $29,6462-6472$.

121. el-Husseini, D., and Bredt, D. S. (2002) Protein palmitoylation: a regulator of neuronal development and function. Nat. Rev. Neurosci. 3, 791-802.

122. Mansouri, M. R., Marklund, L., Gustavsson, P., Davey, E., Carlsson, B., Larsson, C., White, I., Gustavson, K. H., and Dahl, N. (2005) Loss of ZDHHC15 expression in a woman with a balanced translocation $\mathrm{t}(\mathrm{X} ; 15)(\mathrm{q} 13.3$; cen $)$ and severe mental retardation. Eur. J. Hum. Genet. 13, 970-977.

123. Mukai, J., Dhilla, A., Drew, L. J., Stark, K. L., Cao, L., MacDermott, A. B., Karayiorgou, M., and Gogos, J. A. (2008) Palmitoylation-dependent neurodevelopmental deficits in a mouse model of 22q11 microdeletion. Nat. Neurosci. 11, 1302-1310.

124. Buff, H., Smith, A. C., and Korey, C. A. (2007) Genetic modifiers of Drosophila palmitoyl-protein thioesterase 1-induced degeneration. Genetics 176, 209-220.

125. Skene, J. H., and Virag, I. (1989) Posttranslational membrane attachment and dynamic fatty acylation of a neuronal growth cone protein, GAP-43. J. Cell Biol. 108, 613-624.

126. Topinka, J. R., and Bredt, D. S. (1998) N-terminal palmitoylation of PSD-95 regulates association with cell membranes and interaction with K+ channel Kv1.4. Neuron 20, 125-134.

127. Wilkinson, D. K., Turner, E. J., Parkin, E. T., Garner, A. E., Harrison, P. J., Crawford, M., Stewart, G. W., and Hooper, N. M. (2008) Membrane raft actin deficiency and altered Ca2+-induced vesiculation in stomatin-deficient overhydrated hereditary stomatocytosis. Biochim. Biophvs. Acta 1778, 125-132. 
128. Vetrivel, K. S., and Thinakaran, G. (2010) Membrane rafts in Alzheimer's disease beta-amyloid production. Biochim. Biophvs. Acta 1801, 860-867.

129. Vetrivel, K. S., Meckler, X., Chen, Y., Nguyen, P. D., Seidah, N. G., Vassar, R., Wong, P. C., Fukata, M., Kounnas, M. Z., and Thinakaran, G. (2009) Alzheimer disease Abeta production in the absence of S-palmitoylation-dependent targeting of BACE1 to lipid rafts. J. Biol. Chem. 284, 3793-3803.

130. Rajendran, L., Schneider, A., Schlechtingen, G., Weidlich, S., Ries, J., Braxmeier, T., Schwille, P., Schulz, J. B., Schroeder, C., Simons, M., Jennings, G., Knolker, H. J., and Simons, K. (2008) Efficient inhibition of the Alzheimer's disease beta-secretase by membrane targeting. Science 320, 520-523.

131. Chakrabandhu, K., Herincs, Z., Huault, S., Dost, B., Peng, L., Conchonaud, F., Marguet, D., He, H. T., and Hueber, A. O. (2007) Palmitoylation is required for efficient Fas cell death signaling. EMBO J 26, 209-220.

132. Rossin, A., Derouet, M., Abdel-Sater, F., Hueber, A. O. (2009) Palmitoylation of the TRAIL receptor DR4 confers an efficient TRAIL-induced cell death signaling. Biochem. J. 419, 185-192.

133. Patel, H. H., and Insel, P. A. (2009) Lipid rafts and caveolae and their role in compartmentation of redox signaling. Antioxid. Redox Signal $11,1357-1372$.

134. Alvarez, E., Girones, N., and Davis, R. J. (1990) Inhibition of the receptor-mediated endocytosis of diferric transferrin is associated with the covalent modification of the transferrin receptor with palmitic acid. J. Biol. Chem. 265, 16644-16655.

135. Mack, D., and Kruppa, J. (1988) Fatty acid acylation at the single cysteine residue in the cytoplasmic domain of the glycoprotein of vesicular-stomatitis virus. Biochem. J. 256, 1021-1027.

136. Dietzen, D. J., Hastings, W. R., and Lublin, D. M. (1995) Caveolin is palmitoylated on multiple cysteine residues. Palmitoylation is not necessary for localization of caveolin to caveolae. J. Biol. Chem. 270, 6838-6842.

137. Abrami, L., Leppla, S. H., and van der Goot, F. G. (2006) Receptor palmitoylation and ubiquitination regulate anthrax toxin endocytosis. J. Cell Biol. 172, 309-320.

138. Tall, R. D., Alonso, M. A., and Roth, M. G. (2003) Features of influenza HA required for apical sorting differ from those required for association with DRMs or MAL. Traffic 4, 838-849.

139. Porter, J. A., Young, K. E., and Beachy, P. A. (1996) Cholesterol modification of hedgehog signaling proteins in animal development. Science 274, 255-259.

140. Rietveld, A., Neutz, S., Simons, K., and Eaton, S. (1999) Association of sterol- and glycosylphosphatidylinositol-linked proteins with Drosophila raft lipid microdomains. J. Biol. Chem. 274, 12049-12054.

141. Karpen, H. E., Bukowski, J. T., Hughes, T., Gratton, J. P., Sessa, W. C., and Gailani, M. R. (2001) The sonic hedgehog receptor patched associates with caveolin-1 in cholesterol-rich microdomains of the plasma membrane. J. Biol. Chem. 276, 19503-19511.

142. Pepinsky, R. B., Zeng, C., Wen, D., Rayhorn, P., Baker, D. P., Williams, K. P., Bixler, S. A., Ambrose, C. M., Garber, E. A., Miatkowski, K., Taylor, F. R., Wang, E. A., and Galdes, A. (1998) Identification of a palmitic acid-modified form of human sonic hedgehog. J. Biol. Chem. 273, 14037-14045.

143. Porter, J. A., Ekker, S. C., Park, W.-J., von Kessler, D. P., Young, K. E., Chen, C.-H., Ma, Y., Woods, A. S., Cotter, R. J., Koonin, E. V., and Beachy, P. A. (1996) Hedgehog patterning activity: role of a lipophilic modification mediated by the carboxy-terminal autoprocessing domain. Cell 86, 21-34.

144. Miura, G. I., Buglino, J., Alvarado, D., Lemmon, M. A., Resh, M. D., and Treisman, J. E. (2006) Palmitoylation of the EGFR ligand Spitz by Rasp increases Spitz activity by restricting its diffusion. Dev. Cell 10, 167-176.

145. Willert, K., Brown, J. D., Danenberg, E., Duncan, A. W., Weissman, I. L., Reya, T., Yates, J. R., 3rd, and Nusse, R. (2003) Wnt proteins are lipid-modified and can act as stem cell growth factors. $\underline{\text { Nature }}$ $423,448-452$.

146. Zhai, L., Chaturvedi, D., and Cumberledge, S. (2004) Drosophila wnt-1 undergoes a hydrophobic modification and is targeted to lipid rafts, a process that requires porcupine. J. Biol. Chem. 279, 33220-33227.

147. Gallet, A., Ruel, L., Staccini-Lavenant, L., and Therond, P. P. (2006) Cholesterol modification is necessary for controlled planar long-range activity of Hedgehog in Drosophila epithelia. Development 133, 407-418.

148. Chen, M. H., Li, Y. J., Kawakami, T., Xu, S. M., and Chuang, P. T. (2004) Palmitoylation is required for the production of a soluble multimeric Hedgehog protein complex and long-range signaling in vertebrates. Genes Dev. 18, 641-659.

149. Panakova, D., Sprong, H., Marois, E., Thiele, C., and Eaton, S. (2005) Lipoprotein particles are required for Hedgehog and Wingless signalling. Nature 435, 58-65.
150. Zeyda, M., Staffler, G., Horejsi, V., Waldhausl, W., and Stulnig, T. M. (2002) LAT displacement from lipid rafts as a molecular mechanism for the inhibition of $\mathrm{T}$ cell signaling by polyunsaturated fatty acids. J. Biol. Chem. 277, 28418-28423.

151. Lindwasser, O. W., and Resh, M. D. (2002) Myristoylation as a target for inhibiting HIV assembly: unsaturated fatty acids block viral budding. Proc. Natl. Acad. Sci. U. S. A. 99, 13037-13042.

152. Resh, M. D. (2006) Trafficking and signaling by fatty-acylated and prenylated proteins. Nat. Chem. Biol. 2, 584-590.

153. Moffett, S., Brown, D. A., and Linder, M. E. (2000) Lipid-dependent targeting of G proteins into rafts. J. Biol. Chem. 275, 2191-2198.

154. Zacharias, D. A., Violin, J. D., Newton, A. C., and Tsien, R. Y. (2002) Partitioning of lipid-modified monomeric GFPs into membrane microdomains of live cells. Science 296, 913-916.

155. Trabelsi, S., Zhang, S., Lee, T. R., and Schwartz, D. K. (2008) Linactants: surfactant analogues in two dimensions. Phvs. Rev. Lett. 100, 037802.

156. Weise, K., Triola, G., Brunsveld, L., Waldmann, H., and Winter, R. (2009) Influence of the lipidation motif on the partitioning and association of N-Ras in model membrane subdomains. J. Am. Chem. Soc. $131,1557-1564$.

157. Weise, K., Triola, G., Janosch, S., Waldmann, H., and Winter, R. (2009) Visualizing association of lipidated signaling proteins in heterogeneous membranes-Partitioning into subdomains, lipid sorting, interfacial adsorption, and protein association. Biochim. Biophvs. Acta 1798, 1409-1417.

158. Resh, M. D. (1999) Fatty acylation of proteins: new insights into membrane targeting of myristoylated and palmitoylated proteins. Biochim. Biophvs. Acta 1451, 1-16.

159. Mukherjee, A., Arnaud, L., and Cooper, J. A. (2003) Lipid-dependent recruitment of neuronal Src to lipid rafts in the brain. J. Biol. Chem. 278, 40806-40814.

160. Prinetti, A., Iwabuchi, K., and Hakomori, S. (1999) Glycosphingolipid-enriched signaling domain in mouse neuroblastoma Neuro2a cells. Mechanism of ganglioside-dependent neuritogenesis. J. Biol. Chem. 274, 20916-20924.

161. Khan, T. K., Yang, B., Thompson, N. L., Maekawa, S., Epand, R. M., and Jacobson, K. (2003) Binding of NAP-22, a calmodulinbinding neuronal protein, to raft-like domains in model membranes. Biochemistrv 42, 4780-4786.

162. Kordyukova, L. V., Serebryakova, M. V., Baratova, L. A., and Veit, M. (2010) Site-specific attachment of palmitate or stearate to cytoplasmic versus transmembrane cysteines is a common feature of viral spike proteins. Virologv 398, 49-56.

163. Smotrys, J. E., and Linder, M. E. (2004) Palmitoylation of intracellular signaling proteins: regulation and function. Annu. Rev. Biochem. 73, 559-587.

164. Baekkeskov, S., and Kanaani, J. (2009) Palmitoylation cycles and regulation of protein function. Mol. Membr. Biol. 26, 42-54.

165. Planey, S. L., and Zacharias, D. A. (2009) Palmitoyl acyltransferases, their substrates, and novel assays to connect them. $\mathrm{Mol}$. Membr. Biol. 26, 14-31.

166. Levental, I., Byfield, F. J., Chowdhury, P., Gai, F., Baumgart, T., and Janmey, P. A. (2009) Cholesterol-dependent phase separation in cell-derived giant plasma-membrane vesicles. Biochem. J. 424, 163-167.

167. Hammond, A. T., Heberle, F. A., Baumgart, T., Holowka, D., Baird, B., and Feigenson, G. W. (2005) Crosslinking a lipid raft component triggers liquid ordered-liquid disordered phase separation in model plasma membranes. Proc. Natl. Acad. Sci. U. S. A. 102, 6320-6325.

168. Bacia, K., Scherfeld, D., Kahya, N., and Schwille, P. (2004) Fluorescence correlation spectroscopy relates rafts in model and native membranes. Biophvs. J. 87, 1034-1043.

169. Horner, A., Antonenko, Y. N., and Pohl, P. (2009) Coupled diffusion of peripherally bound peptides along the outer and inner membrane leaflets. Biophvs. J. 96, 2689-2695.

170. Cheng, H. T., Megha, and London, E. (2009) Preparation and properties of asymmetric vesicles that mimic cell membranes: effect upon lipid raft formation and transmembrane helix orientation. J. Biol. Chem. 284, 6079-6092.

171. Pautot, S., Frisken, B. J., and Weitz, D. A. (2003) Engineering asymmetric vesicles. Proc. Natl. Acad. Sci. U. S. A. 100, 10718-10721.

172. Hayashi, M., Shimada, Y., Inomata, M., and Ohno-Iwashita, Y. (2006) Detection of cholesterol-rich microdomains in the inner leaflet of the plasma membrane. Biochem. Biophvs. Res. Commun. $351,713-718$.

173. Roberts, W. L., Myher, J. J., Kuksis, A., Low, M. G., and Rosenberry, T. L. (1988) Lipid analysis of the glycoinositol phospholipid membrane anchor of human erythrocyte acetylcholinesterase. Palmitoylation of inositol results in resistance to phosphatidylinositolspecific phospholipase C. J. Biol. Chem. 263, 18766-18775. 